\title{
Sir C. V. Raman Nobel Ceremony Coverage by the European Press
}

\author{
Rajinder Singh* \\ Research Group - Physics Education and Public Understanding of Science, \\ Physics Institute, University of Oldenburg, 26111.
}

(Received 11 August 2019)

\begin{abstract}
Sir C. V. Raman as the first Asian received the Physics Nobel Prize about ninety years ago, in 1930. Till this date he is the only Indian scientist to get this honour, though his other countrymen S. N. Bose, M. N. Saha and H. J. Bhabha were also nominated. C. V. Raman and his wife reached Sweden in the second week of December 1930 to receive the award and stayed in Europe until the end of January 1931. The present article recapitulates the coverage received by Sir C. V. Raman and Lady Raman in Swedish, Norwegian, Danish, German, Swiss and British newspapers.
\end{abstract}

Key words: C. V. Raman, European media, Lady Raman, Nobel Prize.

\section{Introduction}

On February 28, 1928, C. V. Raman and his students observed that when monochromatic light is scattered by a transparent medium, the scattered radiation contains not only the original colours, but also other colours, which give information about the molecular structure of the medium. This effect later came to be known as the Raman Effect. For this discovery and his work on light scattering, C. V. Raman was awarded the Physics Nobel Prize in 1930. Various articles and books exploring different aspects of C. V. Raman's life and science have been written. However, the published literature on Raman did not tell us - what the European newspapers wrote on the Nobel Laureate and his wife, while they were in Europe. The present article intends to fill this gap. ${ }^{1}$

DOI: 10.16943/ijhs/2020/v55i1/152344

*Email: rajinder.singh@uni-oldenburg.de

${ }^{1}$ I would like to mention that the names of the most of the newspapers referred to in the present article are unknown. Most of the documents (Newspaper cuttings) I got from the Raman Research Institute.

\section{Announcement of the winner}

On November 13, 1930, The Associate Press published that C. V. Raman and H. Fischer are declared the Nobel Prize winners for Physics and Chemistry for the year 1930 respectively (Figure 1). Two months before the Prize was announced, C.V. Raman had bought tickets for Stockholm. How Raman came to know that he was going to win the Nobel Prize? This has been discussed elsewhere (Singh 2016, pp. 74-75).

\section{Reception in Stockholm}

Lady Raman recalled that their stay in Stockholm extended for a week from the 9th to 16th December, 1930 (Raman 1988, pp. 33-39). Reports published in newspapers confirm that C. V. Raman (CVR) and his wife

They are referred to as follow: (i) Name of newspaper (if available), e.g. The Advance. Document No. RP-6.53, RRI. (ii) If the newspaper is unknown, only Document No. RP-... is given. 


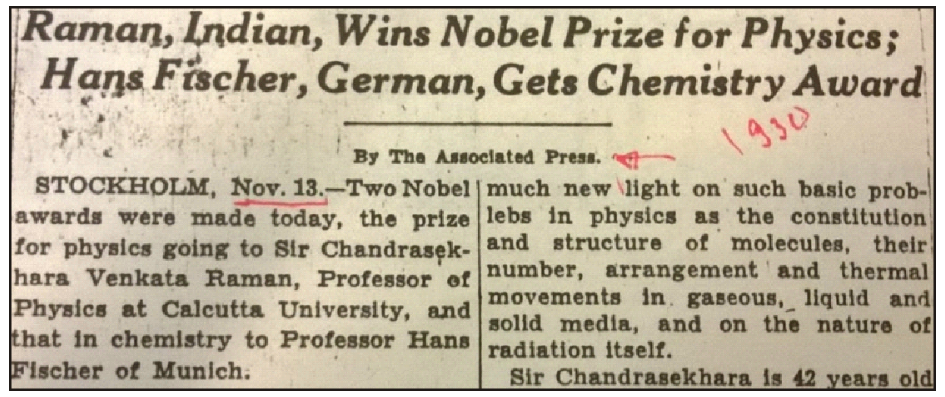

Figure 1 Winners of the Physics and Chemistry Nobel Prizes for the year 1930. Credit: The Associate Press.

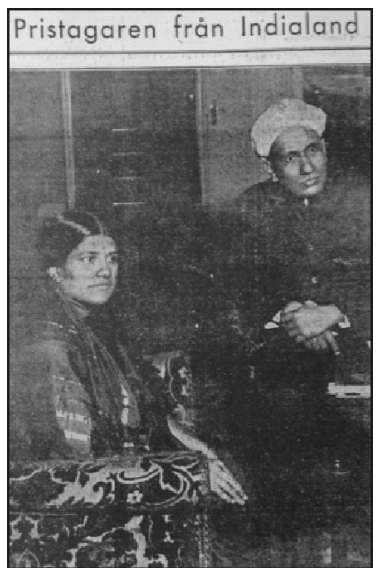

Figure 2 Indian Nobel Prize winner, Professor Sir Chandrasekhara Venkata Raman and Lady Raman after arriving at Carlton Hotel on Tuesday morning. Credit: RRI Bangalore.

reached Stockholm on Dec. 9, 1930. They stayed in the Carlton Hotel. A local newspaper under title "Award winner from India” published two photographs of CVR and his wife (Figures 2 and 3).

At the Carlton Hotel, journalists of the Stockholms Dagblad were interested in knowing about Lady Raman's life. Her comments were published under the title "Nobel Wife - "We Work More Than You!- Never went to school" (Figure 4). It was reported that Lady Raman, despite the strenuous travel, was in a brilliant mood and took long time to talk about her life and women in India. Unfortunately, her interview is not available.

According to the rules and regulations of the Nobel Foundation, the Nobel Prize ceremony takes place on December 10, the day Alfred Nobel died. Raman told journalists that 5000 persons, including the Royal family and

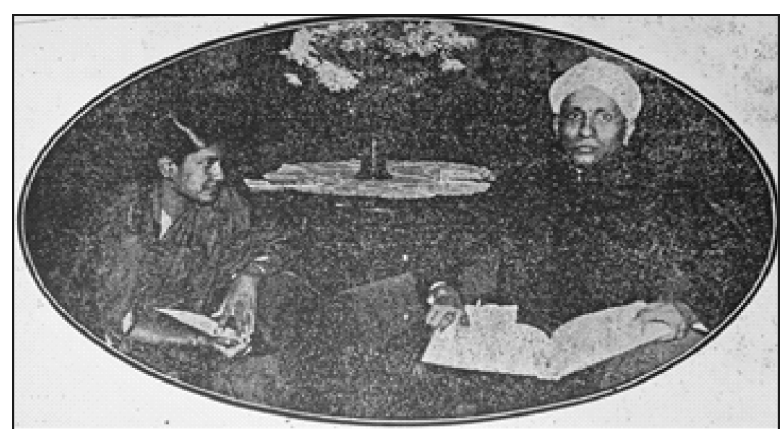

Figure 3 Title of the article was: 'From all over the world the Nobel laureates have come to Stockholm. One of the most distant ways is that of Sir Chandrasekhara Venkata Raman, the Physics prize winner, who has come from India with his wife.' Credit: RRI Bangalore.

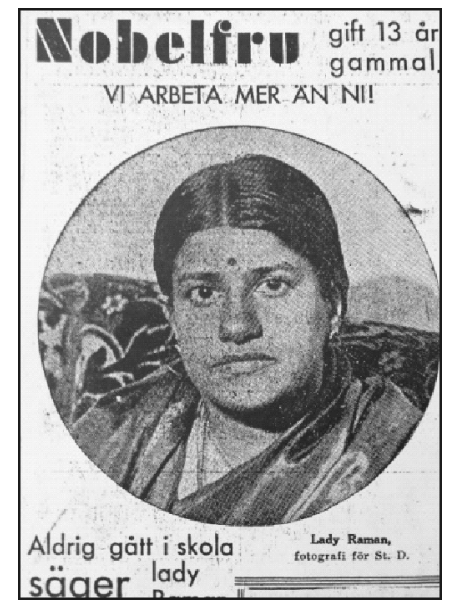

Figure 4 Lady Raman. Credit: Stockholms Dagblad. 


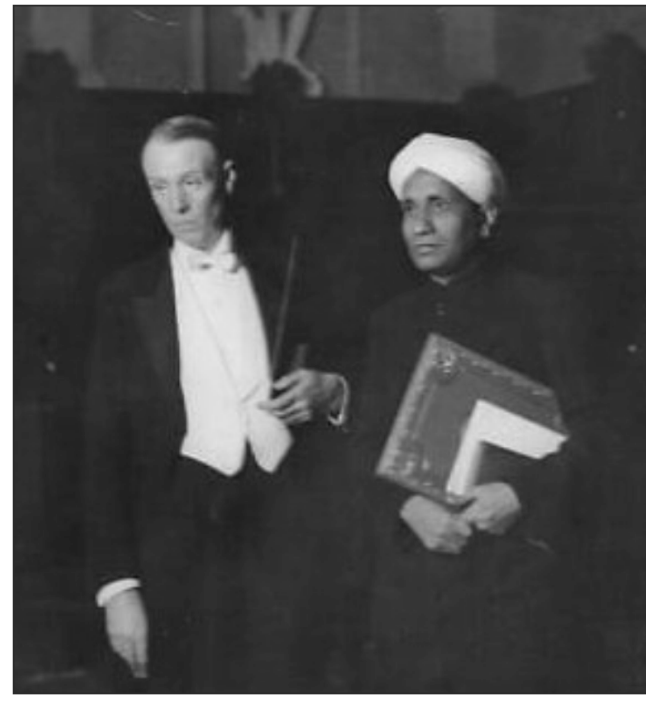

Figure 5 (Left) Sinclair Lewis, the first American to win the Literature Nobel Prize. (Right) C. V. Raman, the first Indian (Asian) to win the Physics Nobel Prize. Credit: RRI Bangalore.

diplomatic dignitaries, took part in the ceremony (Figure 5). Raman and his wife were overwhelmed by the hospitality and attention they received from Swedish press and people (The Advance, Document No. RP-6.53, RRI).

Next day of the award ceremony on December 11, 1930, the dinner party (Figure 6) was arranged and vegetarian foods were served for the Indian guests. In the late evening some selected persons went to the banquet in the City Hall where witty talks were presented. According to Lady Raman, her husband Raman spoke nearly for half an hour on Lord Buddha and his sublime doctrines (Document No. RP-6.76, RRI).

\section{Nobel Lecture by C. V. Raman}

According to the rules and regulations of the Nobel Foundation, a Nobel Laurate has to deliver a lecture within six month of reception of the Nobel Prize. A newspaper reported that Professors Fischer and Raman delivered lectures in their respective fields on Thursday (December 11, 1930). After Fischer's lecture Raman presented his awardwinning discovery popularly known as Raman Effect supplementing it with a large number of images of different spectra. The concluding part of the lecture was devoted to his observations on the refraction of diamonds (Figure 7).
Raman was followed all the time by the press like a popular film star and even while paying to a taxi-driver he was not spared (Figure 8). Under the title "A rupee even" (Figure 8), it was reported in a magazine that "Nobel laureates had a busy day yesterday with lecture and dinner with the king'.

On Dec. 21, 1930, Vecko Journalen published different photographs stating that this year the Nobel Prize ceremony and dinner were more grandiose and eloquent (Figure 9). After the Nobel Prize ceremony, CVR and his wife left for Norway, to meet Professor Vilhelm Bjerknes, a Norwegian physicist and meteorologist.

\section{Visit to Norway, Uppsala and Gothenburg}

CVR was offered a research associate and visiting professor at the California Institute of Technology between September 20, and December 16, 1924 (AR-IACS, 1924). In California, he worked with the Nobel Laureate R. A. Millikan (AR-IACS 1925, pp. 125-126) where he first time met Vilhelm Bjerknes. In Oslo, one of the newspapers reported that the Indian Nobel Prize winner, Professor of Physics at the University of Calcutta, together with his wife arrived from Stockholm with the Continental train on Tuesday morning (Figure 10). Professor Raman would be visiting Uppsala, and perhaps Lund in Sweden.

Other newspaper reported that Raman had come to greet his old friend Professor Bjerknes on a private visit. He delivered a lecture at the physical institute, and shared his current work with a group of scientists. Raman at a press conference in Oslo informed the journalists that from Oslo, he would travel to Gothenburg, Sweden to deliver a lecture at the Technical University. He would be looking forward to meet his old friend Professor Niels Bohr at Copenhagen. In the middle of January 1931, he would be in Glasgow, to receive the honorary doctorate degree. At the end of January, he might return to India, but if he had time, he would spend some days in Germany and visit Munich, Leipzig or Göttingen. He intended to spend a week in Switzerland.

A local newspaper covering Raman's visit to Uppsala reported that Raman delivered a lecture at the PhysicalChemical Institute. Accompanied by Professor Siegbahn, Raman visited the Institute and the castle and had lunch after that (Figure 11). A newspaper in Gothenburg re- 

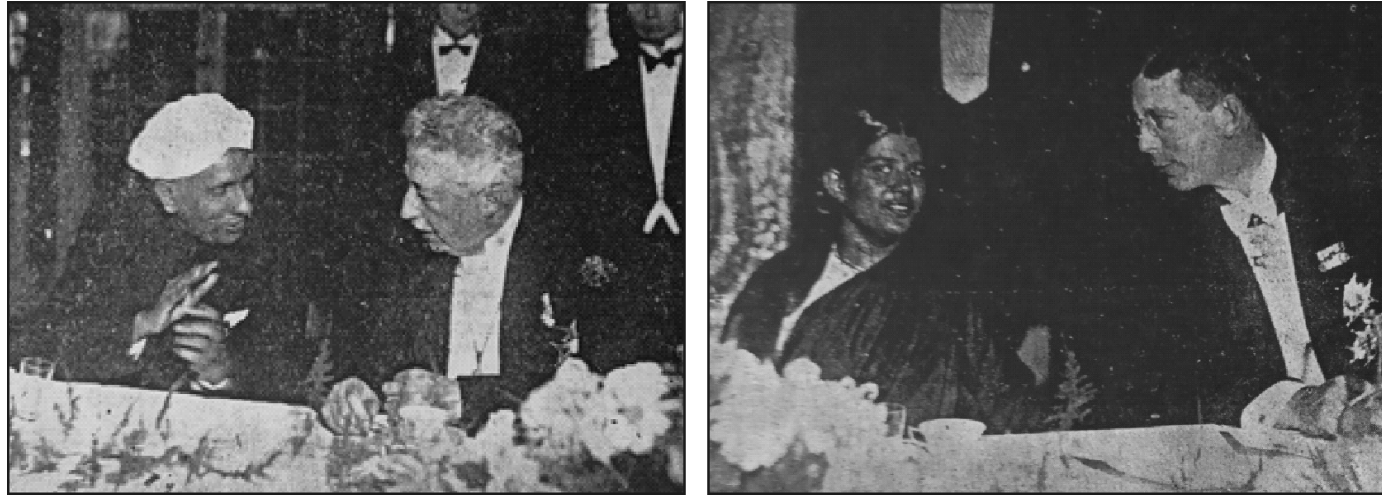

Figure 6 (Left) CVR with the King of Sweden. (Right) Lady Raman with Prince Ingeborg. Credit: RRI Bangalore.

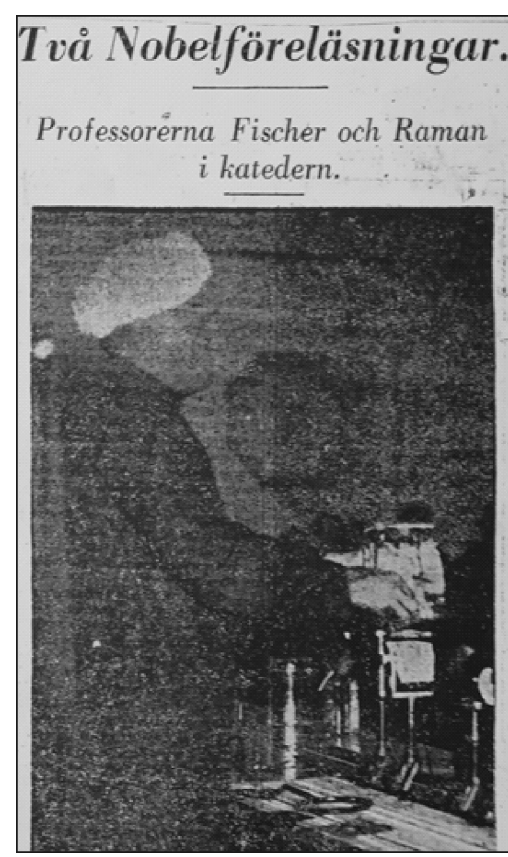

Figure 7 CVR demonstrating his Nobel lecture. Credit: RRI Bangalore.

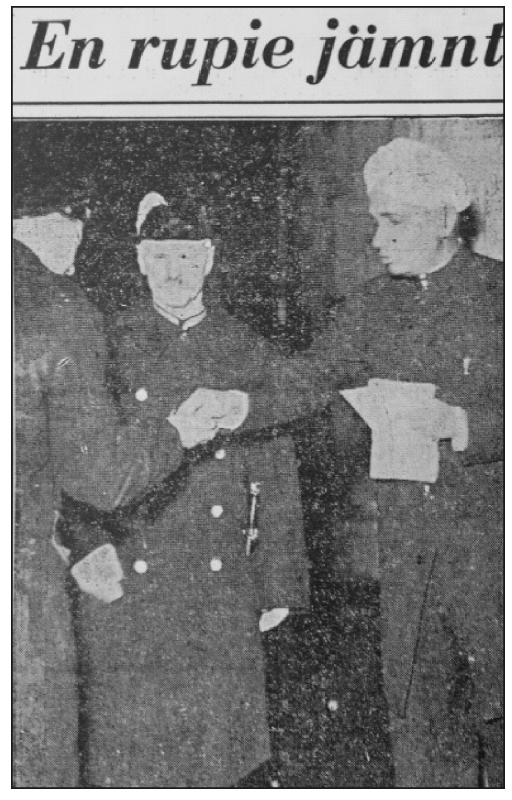

Figure 8 Professor Raman paying the car bill at the castle. Credit: RRI. 


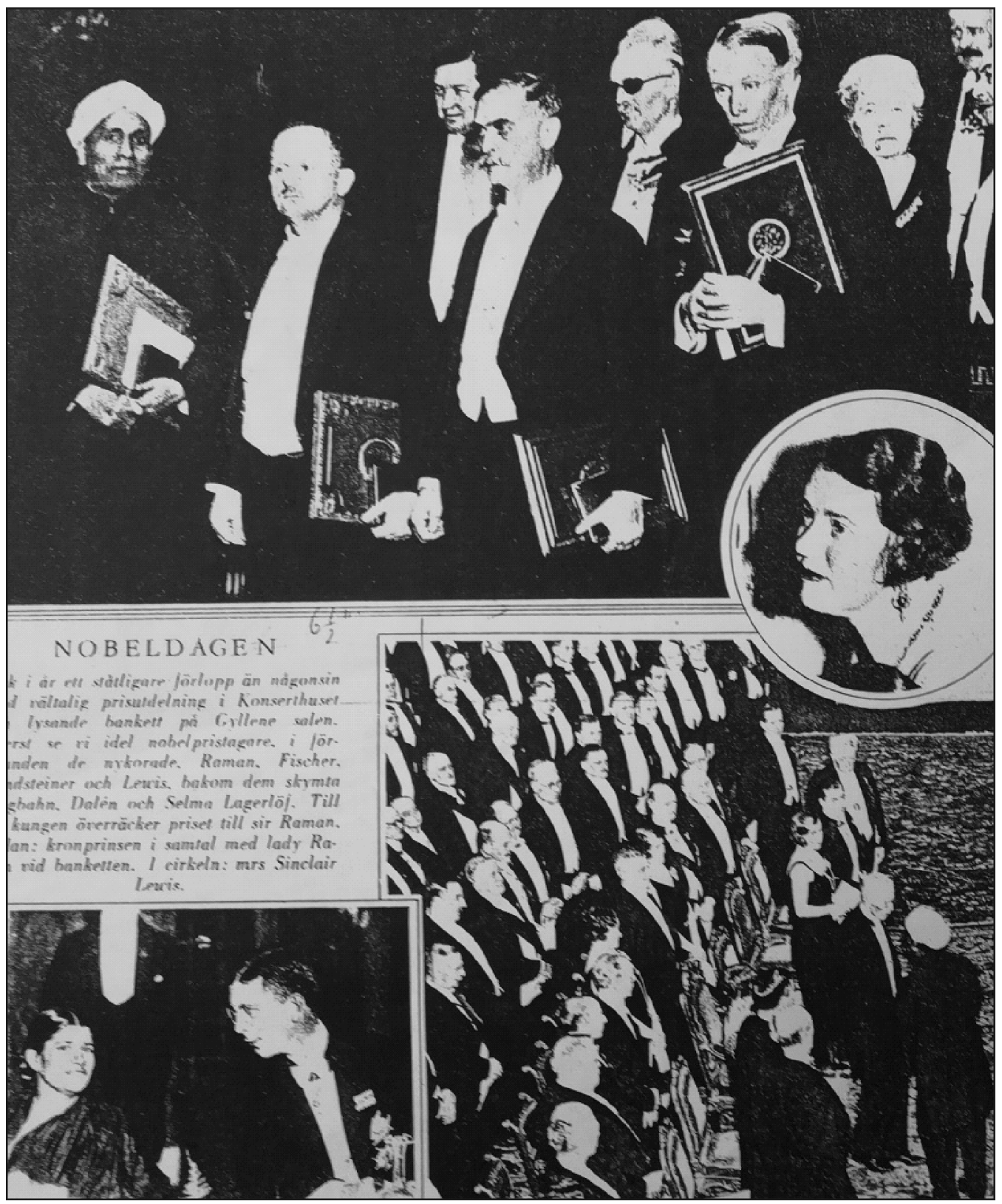

Figure 9 (At the top, in the foreground) Newly elected Nobel laureates - C. V. Raman, H. Fischer, K. Landsteiner (Medicine Nobel Prize winner) and S. Lewis. (Second row) M. Siegbahn, G. Dalen, and S. Lagerlöf. (Bottom right) King awarding the Nobel Prize to Sir Raman. (Bottom left) Crown Prince in conversation with Lady Raman at the banquet. (In circle) Mrs. Sinclair Lewis. Credit: Vecko Journalen. 


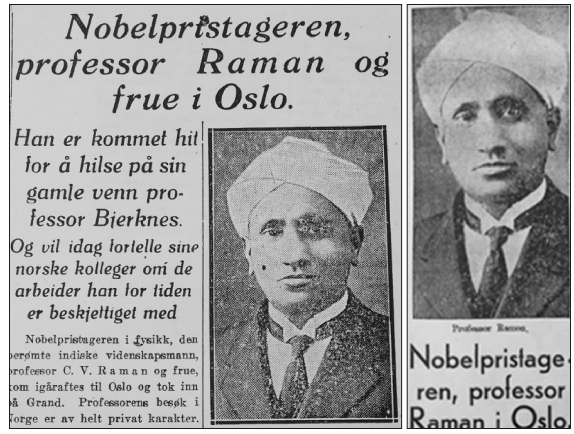

Figure 10 (Left) 'Nobel Laureate, Professor Raman and his wife in Oslo'. (Right) 'Nobel Prize winner, Professor Raman in Oslo'. Credit: RRI Bangalore.

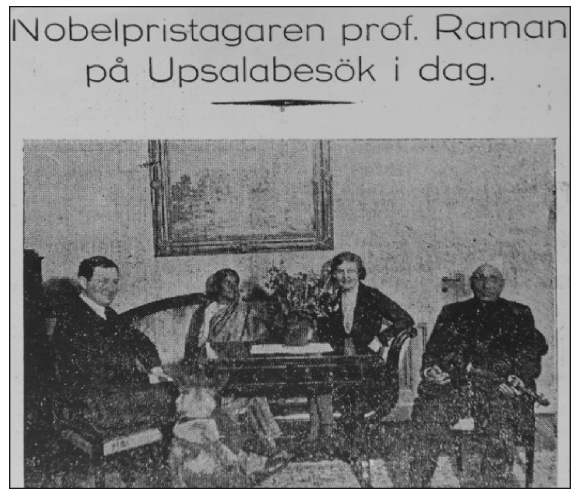

Figure 11 (From left to right) Manne Siegbahn, Lady Raman, Lady Siegbahn and C. V. Raman. Credit: RRI Bangalore.

ported that Professor Venkata Raman and his wife arrived to Gothenburg from Oslo where he was welcomed by a small reception committee, consisting of professors J. A. Hedvall, H. Faxen and A. Bjorkeson. However, other newspaper reported that there was neither official nor academic ceremony over the visit of Indian Nobel laureate Sir Venkata Raman. Engineers were the hosts. Raman delivered a lecture on "Study of the structure of the molecules" in the evening at the Technical Institute followed by dinner with invited engineers and scientists (Figure 12).

The Swedish-English Association hosted a reception in Grand Hotel's salons in the honour of Nobel laureate Sir Venkata Raman and his wife (Figure 13). It was attended by 60 persons including English Minister with his wife, and Professor Peterson from the Nobel Foundation and the Swedish Academy of Sciences. Raman delivered a

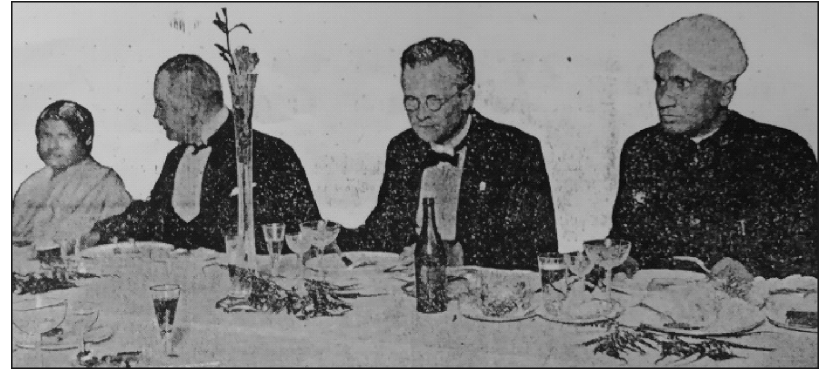

Figure 12 (At dinner. From left to right) Lady Raman, Governor von Sy dow, Professor J. A. Hedvall, and Sir Raman. Credit: RRI Bangalore.

long speech.

\section{Denmark visit and Meeting with Niels Bohr}

C. V. Raman in an apologetic letter had asked Niels Bohr to nominate him for the Nobel Prize so that the prize goes first time to India. Raman at that time was not aware that already in 1928, Bohr had nominated him for the Physics Nobel Prize for the year 1929 (Aaserud 2001, pp. 272-315). On December 17, 1930, Raman wrote to Niels Bohr from Oslo informing that he and his wife had reached from Stockholm last night and intend to stay in Copenhagen for three-four days. In response to Raman's note, Bohr sent a telegram to know the title of Raman's talk, which was to be delivered on Monday. CVR sent the title of his lecture as "Scattering of light in crystals" on December 18, 1930, from Gothenburg via telegram.

Danish newspaper the Berlingske Aften (December 20, 1930), reported that this morning the Indian Nobel Laureate in chemistry (presumably physics), Professor Raman and his wife arrived from Stockholm (Figures 14 and 15). Professor Niels Bohr and his wife visited the Hotel d'Angleterre, and the two great scientists had a long conversation. Professor Raman, a tall, handsome, and youthful looking man was dressed in a tight-fitting long, buttoned black jacket and snow-white turban over the dark face, which reminded directly of orient. On the other hand, Lady Raman was looking completely Indian in her suit with a white tunica and over there a radiant green piece of cloth, around the shoulder like a gown (sārī). Danish newspaper published a long interview where the journalist was more interested in knowing about politics 


\section{RAMAN HOS SVENSK.}

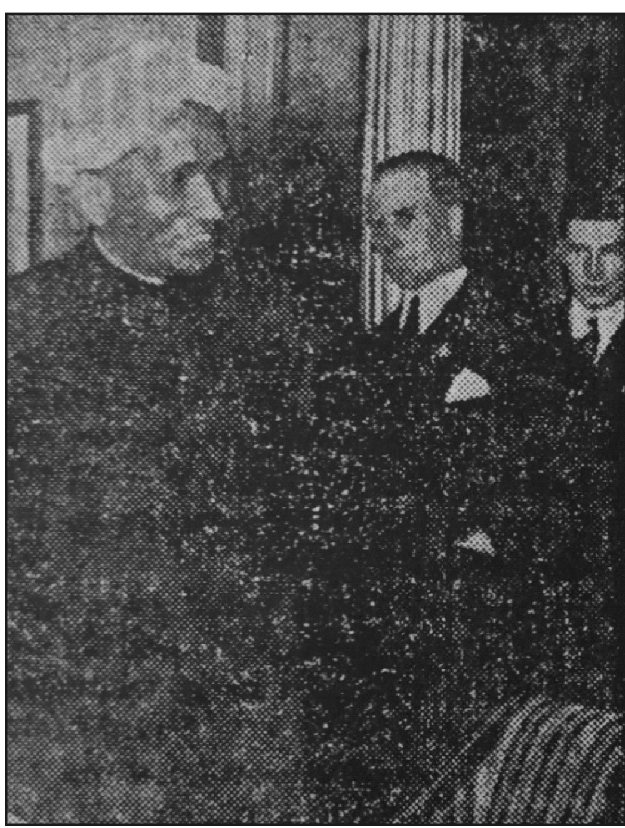

Figure 13 Raman at Swedish-English Association, Gothenburg. Credit: RRI Bangalore.

in India than science. He wanted to know from Raman, whether in the Indian renaissance Hindus and Muslims are united? Raman told: "Yes, on the whole, one has to say that the renaissance, which has come in India in the last twenty years, more or less all the people take part in the movement. The movement is stronger in some provinces than in others."

Raman believed that not politics, but recent achievements in science in India have improved its image at the international level. He stated that it is wrong to believe that the change in India is only happening at political level. There is a rapid scientific development-not just in the field of physics, but also in quite a few other subjects. For example there is a young mathematician Ramanujan, who has already produced impressive scientific work in his short life. There are big names in botany, zoology, medicine, meteorology and so on. Around the same time the first round table conference was held in London from November 1930 to January 1931. Raman was asked, whether he expect something positive for India from the conference? His answer was that he is not a political man. However, he thinks the results of the conference will not

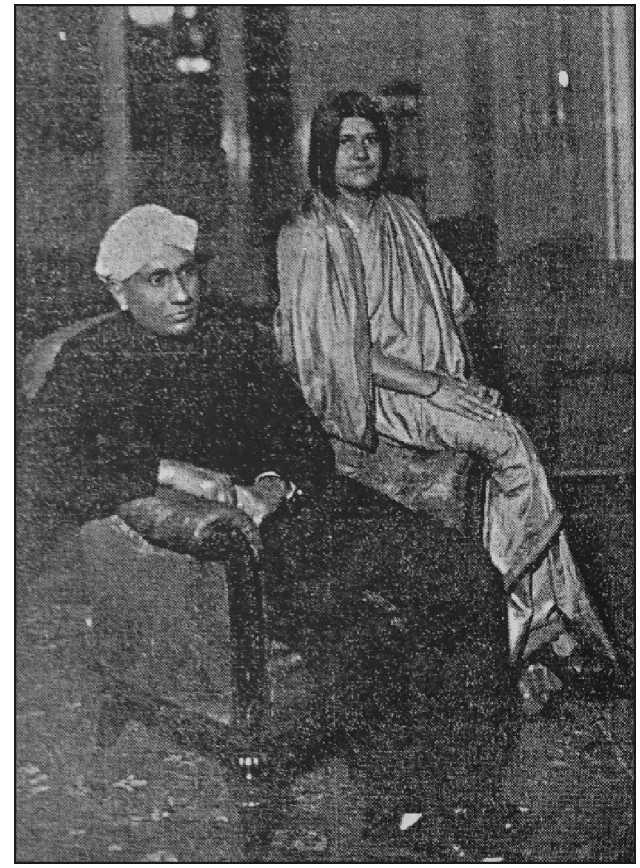

Figure 14 CVR and Lady Raman in Copenhagen. Credit: RRI Bangalore.

satisfy India's national feeling.

About the lecture the local newspaper reported that Professor Niels Bohr had invited his staff and many of well-known physicists at the Department of Theoretical Physics to hear the lecture of the Indian Nobel Laureate, Professor Raman in the afternoon (Figure 16). He talked on the investigations that led to his discovery of diffused radiation, known as the Raman Effect. In the evening, Professor Raman was guest of the Physical Society at the Polytechnic College, and after the meeting, Professor H. M. Hansen invited him for evening meal. As the Christmas season had begun, most of the institutions in Europe were closed, CVR and his wife went to Chamonix from Copenhagen where they spent Christmas holidays. They also visited the Universities of Strasbourg and Paris (The Advance, Document No. RP-6.53, RRI). From there they proceeded to U.K., where the next honour was waiting for Sir Raman.

\section{Glasgow and L.L.D. for CVR}

Clerk of Senate of the University of Glasgow, wrote a letter to CVR on December 6, 1930, in Stockholm mentioning 

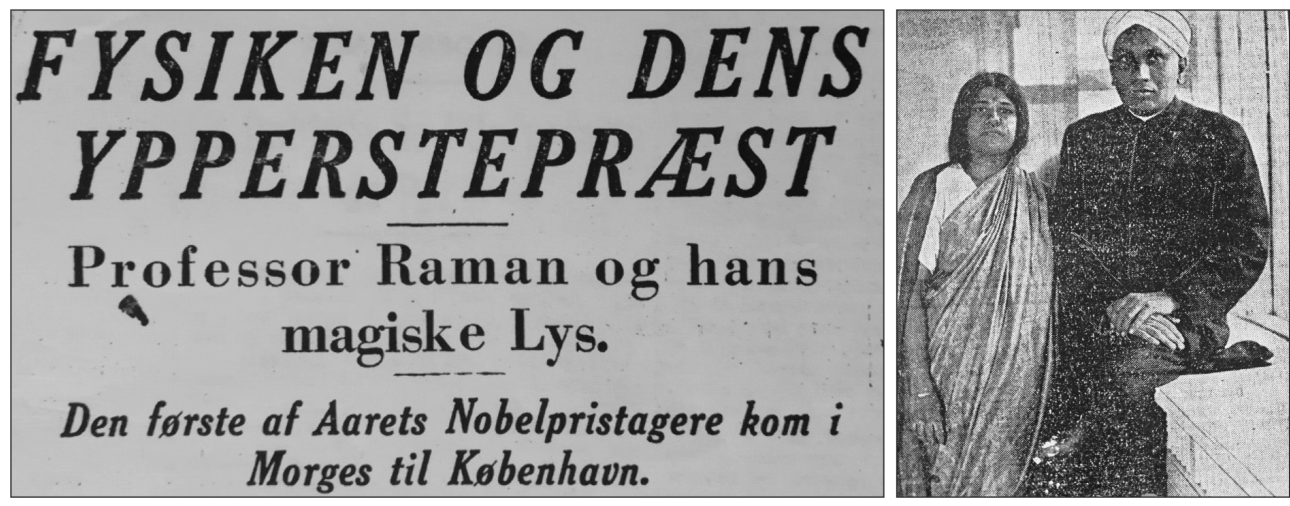

Figure 15 (Left) Danish Newspaper reporting about Raman's arrival in Copenhagen. (Right) Lady Raman and Sir C. V. Raman. Credit: RRI Bangalore.

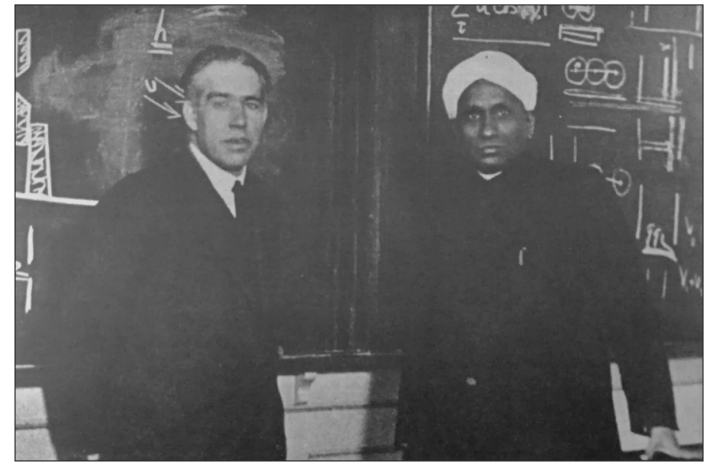

Figure 16 Niels Bohr and C. V. Raman at the Niels Bohr Institute of Theoretical Physics. Credit: RRI Bangalore.

that University was making arrangement to confer upon him the Honorary degree of L.L.D. at a special meeting of the Senate on January 15, 1931(Professor Currie, Clerk of Senate, to C. V. Raman, December 6, 1930.) Raman in a cablegram of November 23, 1930 had told that he would be in at Stockholm on December 10 to receive the Nobel Prize, and would stay in Europe until January 1931 (Minutes of the Senate, University of Glasgow, December. 4, 1930, p. 53). As is evident from Currie's letter of December 18, 1930, CVR in a letter of December 14, 1930 had informed the authorities of the Glasgow University that he would come on January 15, 1931. The Meeting of the Senate was held on Thursday and members present were: Principal - Robert S. Rait; Professor Currie (Clerk of the Senate), Professor Loudon (Dean of the Faculty of Law), and others (Minutes of Senate, January 15, 1931, p. 61). The Honorary Degree of Doctor of Laws was presented to
Sir Chandrasekhara Venkata Raman, F.R.S. by the Dean of the Faculty of Law and the degree was conferred by the Vice-Chancellor with the usual grandeur (Figure 17). Sir C. V. Raman delivered lecture on "The Nature of Light."

\section{Raman in German Speaking Area}

The German community took notice of the Nobel Prize award to CVR (Figure 18). According to a newspaper- It has been announced in Stockholm that the Nobel Committee has decided to award the Physics Nobel Prize to the Indian C. V. Raman. Not every great discovery is honoured with the Nobel Prize. A discovery must be pioneering and open new research area. To the general public, Raman's discovery may not be known, but in reality it is pioneering and fine discovery, which make it possible to study atom nucleus, which until now was based on theoretical hypothesis. In the article details of experimental set up and results were published which suggests that the article was written by a professional scientist.

Arnold Sommerfeld had high respect for Raman, M. N. Saha, S. N. Bose and D. M. Bose. He often supported Indian men of science. Shortly after the discovery of the Raman Effect, he visited India. These details have been explored elsewhere (Singh 2001). CVR had close contact with Arnold Sommerfeld and it is not surprisingly that he went to Munich (Figure 19).

A newspaper wrote - The famous Indian physicist Raman is presently in Munich to visit his colleagues and friends, and to see their work. He is back from his journey from Stockholm, where he was awarded the Nobel Prize 


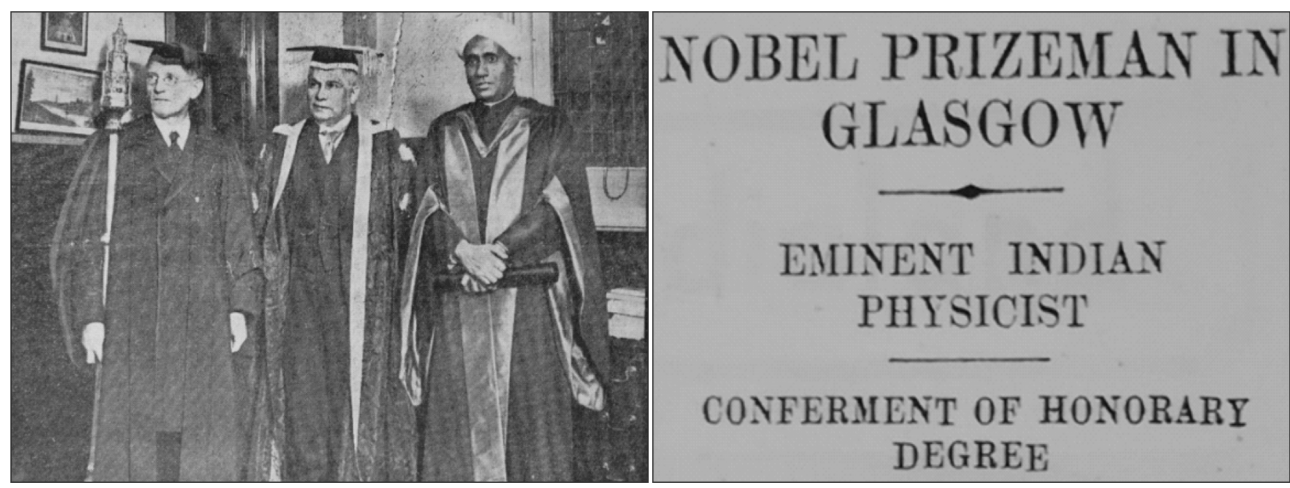

Figure 17 (From right to left) Professor C. V. Raman, Principal Rait (Glasgow University) and Bedellus after receiving the honorary degree of LL.D. Credit: RRI Bangalore.

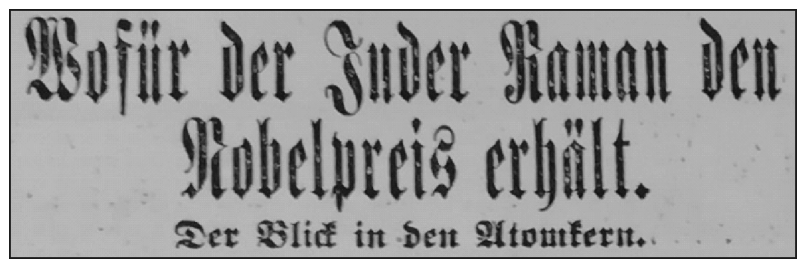

Figure 18 "For what receives the Indian Raman the Nobel Prize. The view into the atomic nucleus". Credit: RRI Bangalore.

\section{Cin inoifider SEelefirter in Mändien}

\section{Drofefior 6. 23. Raman zur Zegrüpung Von Arnold Sommerfeld

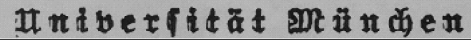

Figure 19 "An Indian scholar in Munich - Professor C.V. Raman welcomed by Arnold Sommerfeld, Munich University”. Credit: RRI Bangalore.

for his discovery- the "Raman Effect." It is the first science Nobel Prize for ancient cultured country India. Before Raman, his countryman, the famous Rabindranath Tagore received the Literature Nobel Prize. According to the article, on Monday morning the rector of the university received the Indian scholar in the presence of professional colleagues. In the afternoon, he was welcomed by the Committee of the German-Indian Academy, which takes care of Indo-German cultural affairs. Tuesday a visit to the Deutsche Museum as well as University was planned. The programme also included a lecture by him for specialists. The author of the article continued that we welcome our guest not only as a successful explorer and discoverer, but also as a representative of the ancient and now rejuvenated culture of the Orient, which works in trust with the culture of the East and strives for the same goals.

Raman delivered a formal talk. What impressed him most was the 'Deutsche Museum'. After his return to India, he recalled it as the museum, where the visitors were asked to "press the button", in contrast to other museum, where you read "please do not touch". This is what Raman told, while talking to a journalist, who wanted to know about his stay in Europe (The Advance. Document No. RP-6.53, RRI).

Austrian physicist Adolf Smekal had congratulated Raman shortly after the discovery as reported in a newspaper in India. Smekal had predicted the effect in 1925 and this was the reason of his interest in Raman's discovery. Thus Raman's visit to Vienna was not a surprise. Unfortunately, not much is known about what newspapers wrote, except a Raman's photograph published under the caption "Bilder der Woche" (Pictures of the Week) (Figure 20). It was reported that the only coloured (black) Nobel Laureate reached Vienna. Raman gave interesting talk in front of a selected audience at the Chemical Institute of the University of Vienna. The talk was on his newest investigations in the field of molecular structure of liquids.

After visiting the above stated cities in Italy - Sicily, Lausanne, Milan and Florence, Sir CVR and Lady Raman reached India via Cairo (Document No. RP-6.76, RRI). The reaction of the Calcutta Media was overwhelming. 


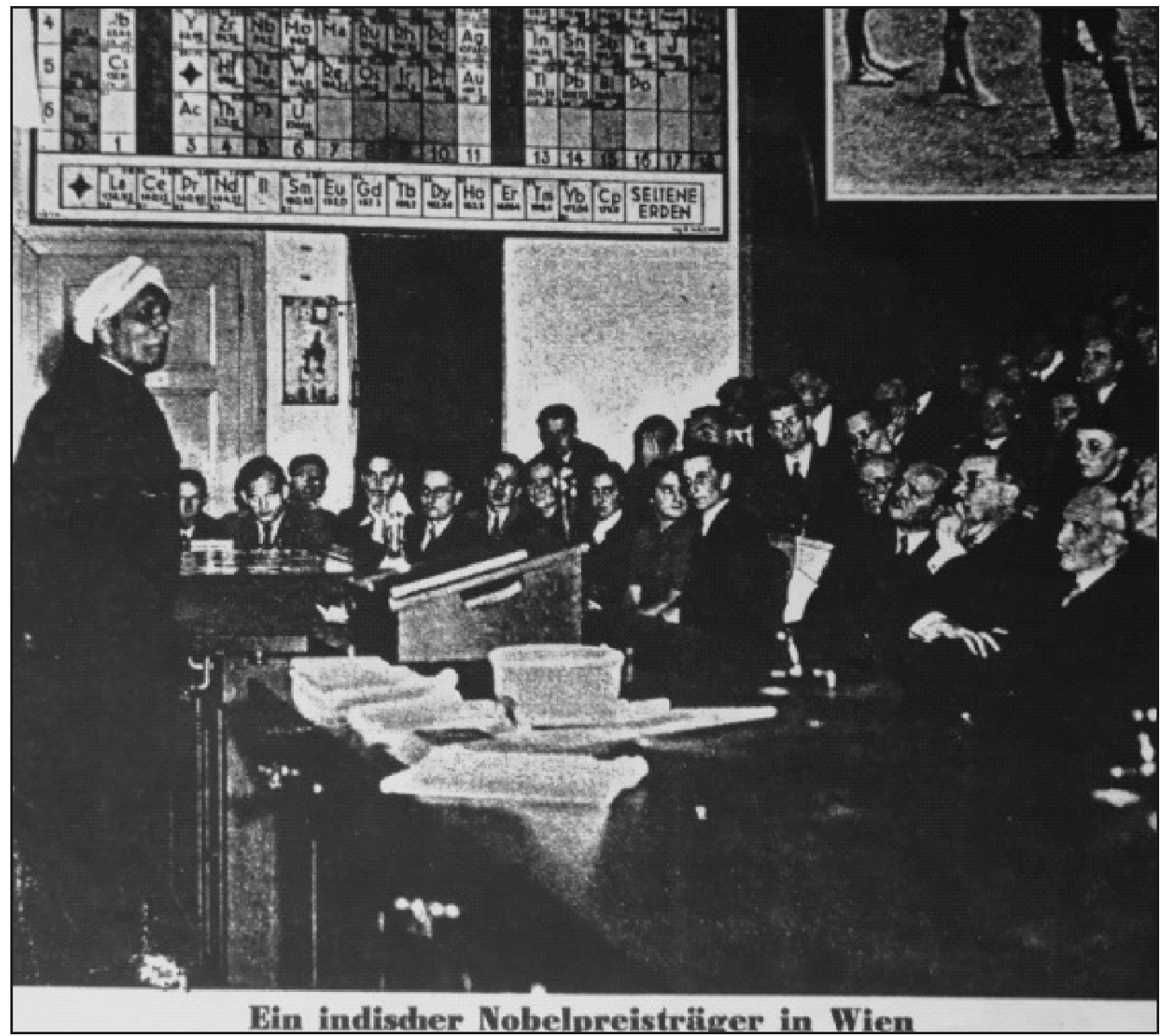

Figure 20 CVR delivering lecture at the University of Vienna. Credit: RRI, Bangalore.

These details have been explored elsewhere.

\section{Conclusion}

C.V. Raman was provided extraordinary reception by the local European media. The main reasons were: (i) $\mathrm{He}$ was the first Asian to win the Physics Nobel Prize. (ii) He belonged to "black" or rather "non-white" Nobel Prize winners. (iii) Raman with his turban and his wife in traditional dress attracted the attention of general public as well as journalists. European media wanted to know from Raman not only about his science but also about Indian culture and politics. He presented his country in high esteem. Within a short period between 9 and 20 December, 1930, he visited different cities in Sweden, Norway, and Denmark. In January 1931, he travelled to France, U.K., Germany, Austria, and Italy and delivered lectures. His lectures were arranged in different countries in short period of time which proves his connection with the scientific community.

\section{Acknowledgement}

In 1998, I visited the Raman Research Institute, Bangalore. The late Professor S. Ramaseshan introduced me to the librarians Dr. A. Ratnakar, Dr. Y. M. Patil, Mrs. S. Geetha, Mrs. S. Girija. They helped me to copy the newspaper cuttings referred to here. Without the help of the members of the library and Professor Ramaseshan support, this work would have not been possible. Thanks are due to the librarian of the University of Glasgow; and Niels Bohr Institute for sending me documents, referred to. I am thankful to Professor S. C. Roy, Kolkata, for commenting and correcting the early version of this paper. 
Thanks are due to Professor M. Komorek, University of Oldenburg, for providing research facilities. Last but not the least, I thank editor-in-chief Indian Journal of History of Science for editorial work.

\section{Bibliography}

[1] Aaserud F. I know how little I have deserved this... in: The History of Thirteen Danish Nobel Prizes - Neighbouring Nobel, Nielsen H., Nielsen K. (eds.), Aarhus University Press, Aarhus, 2001.

[2] Annual Report, Indian Association for Cultivation of Science, 1925.

[3] Raman L. A week in Stockholm, in: The Calcutta Municipal Gazette - C. V. Raman Birth Centenary Special Number, Basak A., Basu J., Basu D., et al., (eds.). The Calcutta Municipal Corporation, Calcutta, 1988.

[4] Singh R. Arnold Sommerfeld - The supporter of Indian physics in Germany, Current Science 81(2001): 1489-1494.

[5] Singh R. Chemistry and Physics Nobel Prizes - India's Contribution, Shaker Publisher, Aachen, 2016.

[6] Singh R. Gandhi and the Nobel Peace Prize, Manohar Publisher, New Delhi, 2018. 